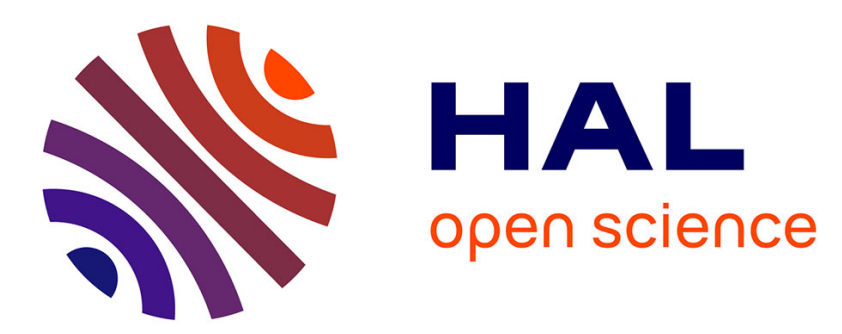

\title{
A Financial Reporting Ontology for Market, Exchange, and Enterprise Shared Information Systems

\author{
Ivars Blums, Hans Weigand
}

\section{To cite this version:}

Ivars Blums, Hans Weigand. A Financial Reporting Ontology for Market, Exchange, and Enterprise Shared Information Systems. 12th IFIP Working Conference on The Practice of Enterprise Modeling (PoEM), Nov 2019, Luxembourg, Luxembourg. pp.83-99, 10.1007/978-3-030-35151-9_6 . hal-03231356

\section{HAL Id: hal-03231356 \\ https://hal.inria.fr/hal-03231356}

Submitted on 20 May 2021

HAL is a multi-disciplinary open access archive for the deposit and dissemination of scientific research documents, whether they are published or not. The documents may come from teaching and research institutions in France or abroad, or from public or private research centers.
L'archive ouverte pluridisciplinaire HAL, est destinée au dépôt et à la diffusion de documents scientifiques de niveau recherche, publiés ou non, émanant des établissements d'enseignement et de recherche français ou étrangers, des laboratoires publics ou privés. 


\title{
A Financial Reporting Ontology for Market, Exchange, and Enterprise Shared Information Systems
}

\author{
Ivars BLUMS 1[0000-0003-3405-0754] and Hans WEIGAND 2[0000-0002-6035-9045] \\ ${ }^{1}$ SIA ODO, Riga, Latvia \\ Ivars.Blums@odo. IV \\ ${ }^{2}$ University of Tilburg, Tilburg, The Netherlands
}

\begin{abstract}
Enterprises operate in markets by building and fulfilling exchange relationships. However, up to date accounting information systems are organized in an enterprise-specific way. We introduce the Market Information perspective on top of the Exchange (Shared Ledger) and Enterprise-Specific perspectives. The latter, developed earlier, are enhanced and the interplay with the Market perspective elaborated. First, we analyze how are Market related concepts of Offering, Contract, Resource, and Social Interaction represented in UFO ontologies and other ontologies. Second, we propose a Market perspective, and included Exchange, and Enterprise perspective conceptual model of a Shared Information System for Financial Reporting in OntoUML language, and third, we analyze the International Accounting Standards Board (IASB) Conceptual Framework and Standards for Financial Reporting to uncover construct deficit and overload in these Standards and Framework for usage in Shared Information Systems.
\end{abstract}

Keywords: IFRS, Conceptual Model, UFO, COFRIS.

\section{$1 \quad$ Introduction}

Enterprises operate in markets by building and fulfilling exchange relationships. Traditionally, information systems support the enterprise by collecting and storing data that is available within the enterprise. This holds in particular for Accounting Information Systems (AIS) supporting internal management and, importantly, Financial Reporting (FR). The financial reports give an overview of the financial position and performance of the firm based on the postings in the ledgers of the enterprise. Whereas nowadays, information systems include more and more external relevant data sources, for instance, market information, the Accounting and Financial Reporting Standards [1] hold to an enterprise-specific point of view.

The objective of general-purpose Financial Reporting is to provide financial information about the Reporting Enterprise, which comprises of:

- Economic Resources controlled by the Enterprise - Assets,

- Economic Obligations - Claims against the Enterprise - Liabilities and Equity Claims,

- Changes within a period in those Assets and Claims - Income, Expenses, and other Equity Changes,

- Enterprise management's stewardship of the Enterprise's Economic Resources. 
This information should be faithful and relevant for existing and potential investors, lenders and other creditors in making decisions relating to providing resources to the Enterprise [2, 3]. Assets and liabilities aggregate information about effects of exchanges in the market and other economic events that create and change exchange offerings, contract obligations, economic resources, and underlying objects. The interpreted and aggregated information is audited [9] and disclosed to the authorities and the market.

From this short description it is immediately clear that the subject of FR exceeds the borders of the enterprise. Claims are claims to or from other parties; they exist in a relationship. So, there is all the reason for shared ledger accounting that takes its starting point not in one or the other party but in the (exchange) relationship. In [7] we have analyzed the advantages of such an approach and have shown how blockchain (DLT) and smart contract technology can support it technically. In this paper, we go one step further and argue that not only the exchanges, but also the market should be included. Markets are not abstract economic entities anymore, but increasingly materialize in platforms and business networks, such as Airbnb and SAP Ariba. With the advent of shared ledger systems and the steady growth of a global information infrastructure, a pure enterprise-specific perspective is becoming obsolete, in our view.

In this paper, we continue building a Financial Reporting Ontology grounded on Unified Foundational Ontology (UFO) and its sub-ontologies. Today, the conceptualization of accounting and Financial Reporting requires precise meaning, enlargement of the scope of concepts and application of new methods for ontological representations to increase interoperability and reuse. What is new in this paper is that we suggest FR to be a subsystem of Market, Exchange, and Enterprise Information Systems, having the FR ontology grounded on upper ontologies and harmonized with Legal, Economic, Business, and IT ontologies, frameworks and standards.

The need for interoperability increases in network-based Market models, such as DLT enabled systems and traditional and new exchange platforms, governmental systems, banks, communities, and corporations of related enterprises, joint ventures, and principal-agent based relationships, all of which require substantial information sharing.

While there are several new papers regarding the development of AIS in blockchain systems e.g., [24, 25], a foundational ontology grounded and fully FR compliant ontology for IS that share Market, Exchange, Business, and FR compliant information does not exist.

Thus, the key research questions for this paper are: (1) how can we benefit from sharing information of Market, Exchange, Business, and Financial Reporting IS; (2) which foundational ontologies, core ontologies, ontological patterns, enterprise related frameworks, and standards can help building a shared IS; (3) what are the deficiencies of current Financial Reporting frameworks and standards when taking the perspective of a shared environment?

In this paper, we continue building a Financial Reporting Ontology grounded on Unified Foundational Ontology (UFO) and its sub-ontologies [12-21]. We introduce the Market Information perspective on top of the Exchange (Shared Ledger) [6,7] and Enterprise-Specific [5] perspectives and extend the COFRIS ontology accordingly.

To demonstrate some of the value of the ontological analysis, we analyze the IASB Conceptual Framework and show where improvements are possible.

Our research methodology is analytical. We analyzed UFO concepts and models, the existing accounting theories, standards, information systems and integrated them into a conceptual model represented in verified OntoUML [13] diagrams and constraints. 


\section{Ontological Foundations Background}

Enterprise ontologies depict the main objects and relationships of an organization and the functions and activities of a business. Enterprise ontologies and standards tend to take an Enterprise-centric perspective. In contrast, UFO social sub-ontologies are based on UFO Social relator, its disposition and manifestations, which support consensual and correlative relationships and interactions among social agents. As such, it is a good basis for market and exchange perspectives that are the objectives of this paper.

In this section, we briefly recapture UFO and discuss some alternative ontologies in order to answer our second research question.

\subsection{UFO Social, Service, Legal Sub-ontologies and Other Relevant Concepts}

OntoUML is a language whose meta-model has been designed to comply with the ontological distinctions and axiomatization put forth by UFO [12]. The combination of builtin stereotypes and constraints of the language enforces conformance, making every valid OntoUML model compliant with UFO.

The UFO-A layer of UFO is the Ontology of Endurants. Endurants are entities that exist in time and can change in a qualitative way while maintaining their identity. Objects or Substantials (e.g., Satya Nadella, his car, the Microsoft Corporation), Relators (e.g., Nadella's employment contract with Microsoft, his car ownership) and Qualities (e.g., Nadella's age, Nadella's car market price) are examples of Endurants.

Kinds are types that classify their entities necessarily and provide a uniform principle of identity for their instances. Instances of a kind can (contingently) instantiate different Roles in different relational contexts. This distinction between necessary and contingent types applies to all Endurants and to Relators in particular. For example, while an Employment Contract (e.g., the one connecting Nadella and Microsoft) is necessarily so, it can contingently be classified as an Offered Contract and as an Agreed Contract. Relators (as well as Qualities/Modes) are existentially dependent entities. The Relator of Nadella and Microsoft can only exist if both Nadella and Microsoft exist.

According to UFO-C, the Sub-ontology of Intentional and Social Entities [14], the exchange of Communicative acts creates Social moments such as Commitments and Claims that inhere in the Social agents involved in these communicative acts. Social agents are Parties' Roles played by Human agents and Institutional agents.

Two or more pairs of mutually dependent Commitments and Claims form a kind of social relationship between the social individuals involved and is termed a Social relator [14]. Social relators are important for our consideration because they are grounding Legal relators that in turn are grounding Economic relators. The latter underlie relationships required for our ontology.

A Commitment (internal or social) is fulfilled by an agent $\mathrm{A}$ if this agent performs an action $\mathrm{x}$ such that the post-state of that action is a situation that satisfies that Commitment's goal. Appointments, are Commitments whose propositional content explicitly refers to a Time interval, and Complex Closed Appointments are composed of a number of Commitments that should be achieved by executing a number of actions of a particular type, under certain types of situations (on the occurrence of a certain triggering event).

Beyond the Ontology of Endurants, UFO also comprises an Ontology of Events as past occurrences (UFO-B) [17]. UFO-B, especially in its new OntoUML 2.0 realization $[13,17]$, facilitates the building of behavioral models of exchange scenarios. 
As noted earlier, conventional accounting is based on a functional classification of transaction effects (recognition) and valuation (measurement) in accounts. In contrast, besides its more faithful and objective character, event information allows the enterprise to benefit from local, cumulative, contextual, and modal properties of events [18] that happen in a market scene [19] and cannot be reduced to properties of their participants' qualities. In particular, to satisfy the growing needs of FR to determine whether an event is unique, infrequent, unusual, routine and whether it could have a continuing effect on routine and frequent business activities of the enterprise [3], grounding must be established in the history and disposition of events.

UFO-S is the Core Ontology for Services [14], which characterizes service phenomena by considering service commitments and claims established between a service parties - provider and a customer along with the service lifecycle phases: Offer, Negotiation/Agreement and Delivery that provides an outline for our Economic Exchange lifecycle model [5]. The detailed exchange scenarios, resources and obligations, their recognition and measurement are outside the scope of UFO-S.

Some Legal aspects of Service Contracts were further elaborated in [16] within the UFO-L Legal Ontology, which is based on Hohfeld/Alexy's theory of fundamental legal concepts. A central element of UFO-L is the notion of legal relator, which is a social relator that is composed of externally dependent legal moments, each of which represents a legal position. The legal positions of UFO-L subsume Claims and Commitments (Rights and Obligations in COFRIS), i.e., Claim-Right and Duty, Permission and NoRight, Power and Subjection, Immunity and Disability, respectively. The above-mentioned Right and Obligation pairs form Correlative associations [16], which are legal foundations and benefits of the shared perspective.

UFO [20] describes Resource as a role that an Object plays [or could play] in an action needed to make progress towards the goal. More specifically, Resource is defined as a type-level entity, capturing the role of an (agentive or non-agentive) Object in the scope of a material relation or in the scope of an event [6]. The Object type is restricted to an "allowed type". In FR Resources are represented as Rights over the Objects [2].

UFO [20] regards Product as a subtype of a Resource restricted by creation or change participation. As stated in e.g., ArchiMate [26] a Product represents a coherent collection of (resources) - services and/or passive structure elements, accompanied by a contract/set of agreements which is offered as a whole to (internal or external) customers. From an Enterprise FR perspective, a Performance Obligation of a Contract specifies Product Type. A Contract Asset and Revenue can be recognized, when a Performance Obligation is fulfilled, i.e., Product (collection of services and goods) transferred.

\subsection{Other Relevant Ontologies (not Grounded in UFO)}

REA - ISO/IEC 15944-4:2015 [26] Business transaction scenarios -Accounting and economic ontology, introduces economic resources, events, and agents, for business transaction scenarios. Obligations and Claims are described in REA [26] as entities optional to "ontological completeness". Transaction scenarios of exchange lifecycle phases are elaborated in ISO in more detail than in UFO-S.

However, the concepts of assets and liabilities and their economic disposition, perhaps the core of accounting and FR, are not regarded. Thus, REA is sometimes viewed as an "operational ontology" [22] and suggested to be augmented by concepts relevant for accounting and FR by OntoREA [28]. 
FIBO Standard for Financial Industry [27] covers Assets and Enterprise-Specific modeling, but neither Economic Resources, nor Contract Fulfillment scenarios.

The PROV Ontology [8] introduces a set of concepts to represent provenance information in a variety of application domains. The main concepts and their relation to our ontology is shown in Fig. 1.

The e3value approach supports the modeling of value networks based on the e3value ontology $[10,11]$. It takes an independent view of the enterprise, interestingly assumes an aggregation level of "network" on top of individual enterprises and stresses the importance of reciprocity in value transactions. Although e3value is useful for exploring business models, it is not sufficiently detailed for accounting and FR purposes.

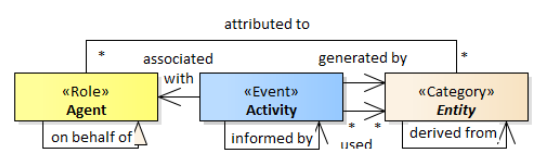

Fig. 1. The Main Concepts of PROV Ontology.

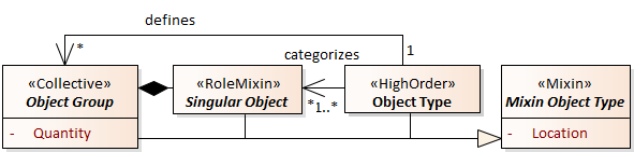

Fig. 2. Mixin Object Type Pattern.

\section{COFRIS v. 0.3. Economic Phenomena}

This section describes the COFRIS v. 0.3 redefinition and extension of our Exchange ontology [5] in a shared environment, using OntoUML. We first introduce a view on Market, Exchange, and Enterprise IS. After having clarified some ontological choices, we present an integrated conceptual model of (business) economic phenomena (Fig. 4) and describe it in separate subsections for each of the three IS distinguished.

\subsection{Market, Exchange, and Enterprise Shared Information Systems.}

Traditionally, the AIS takes an internal enterprise-specific perspective to produce financial statements and uses audit to reconcile with exchange and market perspective. Nowadays exchange and market information becomes more and more available and reliable for independent gathering of enterprise related information. Economic activities and relationships should be captured in Market, Exchange and Enterprise Information Systems. This vision is schematized in Fig. 3, explained below.

The Market IS includes facilitation and recording of exchanges carried out with Market IS involvement. Market IS aggregates them and other disclosed Economic Exchange and Enterprise Experience, including Financial Reporting, Offering, and Market Participant, Contract Obligation, Resource, and Underlying Object Register information. The aggregation results in typification and Market Experience that is communicated back to Market Participants for instantiation as Market Regulations, Exchange, Contract Obligation, Resource and Underlying Object Types. Typification occurs because the market information is not about an individual transaction and involved prices but is on a generic level - such as "the" market price of some resource type.

Information in the Exchange IS is correlative and consensual - symmetrical and agreed among the exchange parties and covers the whole lifecycle of Economic Exchange dispositions, activities, and participants - Offerings, Contract Obligations, and Resources. The exchange and market information undergo [de] recognition, [re] classification, and [re] valuation in Enterprise IS, according to FR Standards. 


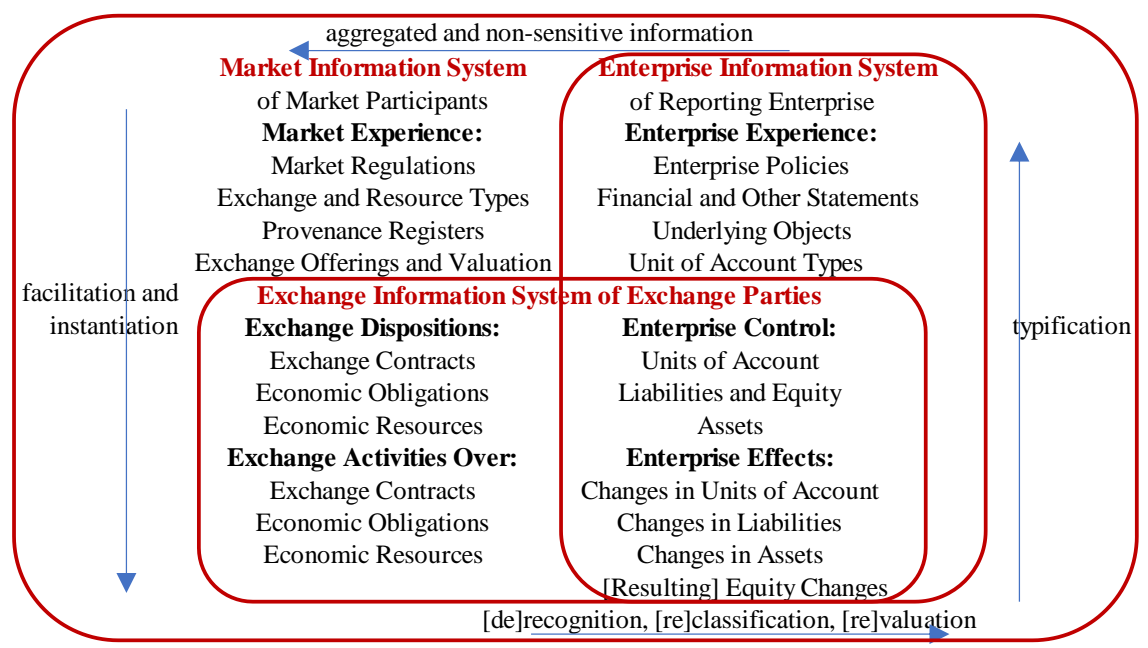

Fig. 3. Market, Exchange, and Enterprise Shared Information Systems.

The information in Enterprise Financial Reporting IS is Enterprise-Specific and interpreted per Financial Reporting Standards, Enterprise's Restrictions, Business Model, Policies, Capabilities, Intentions, and generally is neither correlative nor consensual with other Market Participant information. Current FR Standards neither require the capture of a full lifecycle of an economic exchange, nor object provenance, in a systematic way. Instead of capturing information about transactions and events, conventional accounting recognizes, classifies, and valuates prescribed transaction and other event effects in assets, liabilities and equity [4].

The fair valuation of assets and liabilities is presently required in FR and is inevitably tied to a customized market valuation of similar resources and obligations. Until recently market valuation was readily available only in commodity and stock markets, but networks of Market IS open up a new possibility of provenance and typifying of economic exchanges, obligations, resources and obtaining valuation.

The non-sensitive information produced by FR IS can be communicated for mutual benefit to the Exchange and Market IS on a deeper scale and semantics than existing FR.

The importance of observing transactions in the Exchange IS and Market IS context is increasing because their information is becoming more faithful, immutable and more easily captured in Market, Exchange, and Business IS by other than accounting departments. Note that the information of such transactions is grounding, but not substituting, the accounting recognition and measurement.

\subsection{Some Ontological Choices of our Core Ontology}

In COFRIS the social relator is assumed to be: CORRELATIVE - meaning that one PARTY's Commitment and its FULFILLMENT is a COUNTERPARTY's Claim and its FULFILLMENT and vice versa, CONSENSUAL - meaning that the Commitment and the Claim and their FulfiLlment are AGREED among PARTIEs. Social relator can be OFFERED - meaning that the Commitment is committed (OFFERED) by one PARTY but not yet agreed by the COUNTERPARTY. 
The Social Relator Life can proceed through several instantiation phases. Thus, the SOCIAL RELATOR TYPE instantiated and communicated to the community by an agent qua offeror will become an OFFERED Social Relator, accepted by the claimer - AGREED Social Relator, and further possibly LAPSED, SUSPENDED, ENFORCED, BREACHED or FUlFILlED. For a Complex Closed Appointment, we will distinguish the COMPLEX or CONTRACT FULFILLMENT of all Products committed, PERFORMANCE FULFILLMENT of a sub-goal of a particular Product committed and TRANSFER FULFILLMENT of particular Resource for Performance Fulfillment committed.

Commitment captures the social meaning of FULFILLMENT and assumes providing benefits (products including services) for a COUNTERPARTY. ECONOMIC COMMITMENT [5] assumes a return for providing a benefit (or sacrifice) - a VALUE RIGHT (OBLIGATION) of a PARTy. Thus, Economic Commitment is a Conditional Commitment to EXCHANGE a FULFILLMENT for a VALUE ACCRUAL.

A reciprocal social relator [14], called an ECONOMIC RELATOR [7] is implied to model economic relationships between Market Participants relating Transfer Dispositions over an Object, and Value Accrual. Economic Relator captures Offering, Contract Obligation and Property grounded dispositions to exchange Rights (resp, Obligations) over an Object for Value Rights (resp, Obligations).

To simplify presentation in OntoUML diagrams we introduce some conventions:

- A COMPOSITION relationship may be used even there is only one part;

- An INSTANCE OF (SUBTYPE OF) relationship is not shown if a type and the corresponding instance (type) is associated with an event that instantiates (subsumes) that type.

- OntoUML diagrams represent Types. When we add TYPE to the name of a concept, that means that it is a higher-order or order-less type (and INSTANCE OF relationship between them) in a sense of Multi-Level Type Theory (MLT) [21].

- A particular MIXIN OBJECT TYPE pattern, in analogy to the one in [15], is used, that combines object types with higher-order types. Such a combination is used in situations when either a type or an instance is specified (see Fig. 2). An example is a contract of buying a (yet to be produced) car of a specified model or an existing car.

- The diagrams contain four types of entities: Economic Relators, depicted in green; Economic Events - events that create and change Economic Relators - depicted in blue and having BEGIN and END points as properties, Market Participants (Economic Agents) depicted in yellow, and other Objects depicted in beige or as properties.

\subsection{Market Information System}

MARKETs are institutions in which human or institutional agents exchange valued ECONOMIC RESOURCEs. The concept of MARKETs, however, is wider than the concept of exchange because it includes the structural macro-effects that result from a large number of exchanges, for example changes in the overall price level ${ }^{1}$. Market IS facilitate exchanges, and large number of exchanges and their dispositions aggregate in market experience - types and instances of offerings, contracts, economic exchanges, products, resources, and underlying objects as well as their valuation and risk.

The ultimate location of the Market IS is the net.

\footnotetext{
${ }^{1}$ https://plato.stanford.edu/entries/markets/
} 
For instance, Airbnb ${ }^{2}$ provides a platform and rules for hosts to accommodate guests with short-term lodging and tourism-related activities. It publishes the offerings of the hosts, controls booking and payments, maintains a shared ledger of transactions, assists solving cancelation and breach situations, enforces international law, withholds service fees of Market IS and possibly taxes, and most importantly - aggregates (typifies resources) and publishes Market Prices assessed by the Aerosolve application, that optimizes the exchange for all participants.

The market valuation ascribed to particular (type of) lodging can be used not only for publishing an offering but also for assessing the fair value or impairment adjustment of a resource for financial reporting. Such fair value could be more objective than the one assessed by the holder due to limited information, method or subjective intentions of a participant. The Market IS has an interest in determining the most objective price to facilitate exchange.

The product - lodging services, that mainly consist of the provided facility and the services of the host, is exchanged for the payment and usage habits of the guest. Exchangeable resources are mutually described ex ante and reviewed ex post. These descriptions and reviews form the history of exchanges, products and participants, create and maintain the resource type, risk and valuation. Based on the history or other circumstances, the offering can be accepted/rejected by either party. Again, the Market IS is interested to maintain objective, symmetric information.

This Market IS application aggregates and typifies transaction participant (economic agent and resource) properties and local, cumulative, contextual, modal properties of transaction events that happen in this market scene.

Following [7] we define MARKET PARTICIPANTs (or Economic agents) as social agents - persons and policy regulated enterprises, contractual groups of people and enterprises, rule regulated markets, or the society at large, regulated by law.

All institutional Market Participants are identified, and their history maintained in the Market $\mathrm{IS}^{3}$. Market Participants hold economic resources, against and toward other Market Participants.

ECONOMIC RESOURCE (TYPE), a sub-kind of Economic Relator, represents (a) a BUNDLE OF RIGHTs within a spatiotemporal region and in a PRINCIPAL MARKET, over (b) an OBJECT (TYPE), that have a disposition to be transferred in exchange for (c) a VALUE ACCRUAL.

Besides valued property rights of usage and transfer over an object, economic resource can represent consensual rights to receive (resp., correlative transfer obligations of a converse party):

1) conditional right to receive a resource, product, or contract fulfillment (resp., obligation to transfer, performance, or contract obligation) of a specified type in exchange for value accrual;

2) right to accrued value for transferred resources (transfer value, revenue, or contract consideration);

3) unconditional right to receive a product of a specified type, for exchanged value (transfer, performance, or contract claim).

An Economic Resource IS HELD by a Market Participant AGAINST another Market Participant - a Debtor, Society, or Any who has a Correlative Obligation to the Holder.

\footnotetext{
${ }^{2}$ https://www.airbnb.com/ and http://airbnb.io/aerosolve/.

${ }^{3}$ Legal Entity Identification: see https://www.gleif.org
} 
Underlying OBJECT, denotes a physical or social UFO::OBJECT. Note that an INTELLECTUAL PROPERTY, EXCHANGE TYPE and CONTRACT itself can also be an underlying OBJECT. Qualities and Functionality of the OBJECT prescribe the allowed activities and the allowed Roles that are physically and socially possible.

BUNDLE OF RIGHTs (and correlative Obligations) prescribe legally empowered and permissible (resp, obliged) activities and roles, and should be fulfillment able.

VALUATION of Value Accrual TOWARD Principal Market Participant Type should be financially feasible, realizable, and settlement able.

Product OR PERFORMANCE Right and correlative PERFORMANCE OBLIGATION comprises a coherent collection of several Rights to receive (Transfer obligations) offered or contracted as a whole aimed at creating a Product useful for the Target Customer.

The reciprocal performance obligations of parties - market participants are combined into EXCHANGE TYPEs. Exchange types are instantiated into EXCHANGE OFFERINGs by a particular OFFEROR, for specified product types, and addressed toward TARGET parties in the market. The AGREEMENT of an offering by two parties creates an EXCHANGE CONTRACT that is to be fulfilled by mutual transfers of bound parties.

The market is a truth-maker of a product and thus involved resources. In the Airbnb example: (a) the proof of rights of the product is not requested - their absence will be revealed in process, (b) the functionality of the lodging object is published, (c) the market valuation is established based on typification of the offering and the context, and further maintained involving particular experience. Notice that the resource, price and the target customer type are for the Principal Market, i.e., Airbnb, but not, e.g., Booking.com.

TIMING represents the time interval of rights - the begin and end date of availability and thus depicts TRANSFER due date or triggering condition. LOCATION or address refer to place where the rights are available to the Holder.

Economic Exchanges and their dispositions, and other Economic Events, i.e. those that change Economic Resources, produce MARKET EXPERIENCE that is a base for a Market assessment of VALUATION and UNCERTAINTY, and formation of EXCHANGE and PRODUCT TYPES. However not all Economic Phenomena are captured in the Information Systems and not all such Phenomena are disclosed to the Market IS or are disclosed in the aggregated form only. EXCHANGE TYPEs have a rather extensive MLT [21] hierarchy, having a core ontology at a top level, that is specialized by different IFRS Standard Ontologies, such as Trade, Lease, Insurance, and Financial Instrument Contracts, further specialized by ENTERPRISE POLICIEs. The latter, together with the Financial Statements and Notes, must be disclosed in FR and to the Market IS per FR Standards [1]. Within Market IS an exchange type taxonomy should be maintained and reported by the holder and the provenanced objects maintained.

Market in a most general sense contains market participant businesses as products. The financial statements form part of enterprise description and history. Transactions include business combinations and security trades. In addition, financial statements, notes, mandatory and voluntary legal disclosures, reveal rather large amount of information that could be used for accumulating exchange, product and object type and valuation information, and hence to improve financial reporting.

EXCHANGE TYPE characterizes party and counterparty market participant types of exchange, obligations taken and fulfilled, economic resource types promised and transferred, as well as object types underlying those resources. For certain types of exchanges shared instances of exchanges, obligations, resources and underlying objects are kept in public registers. 


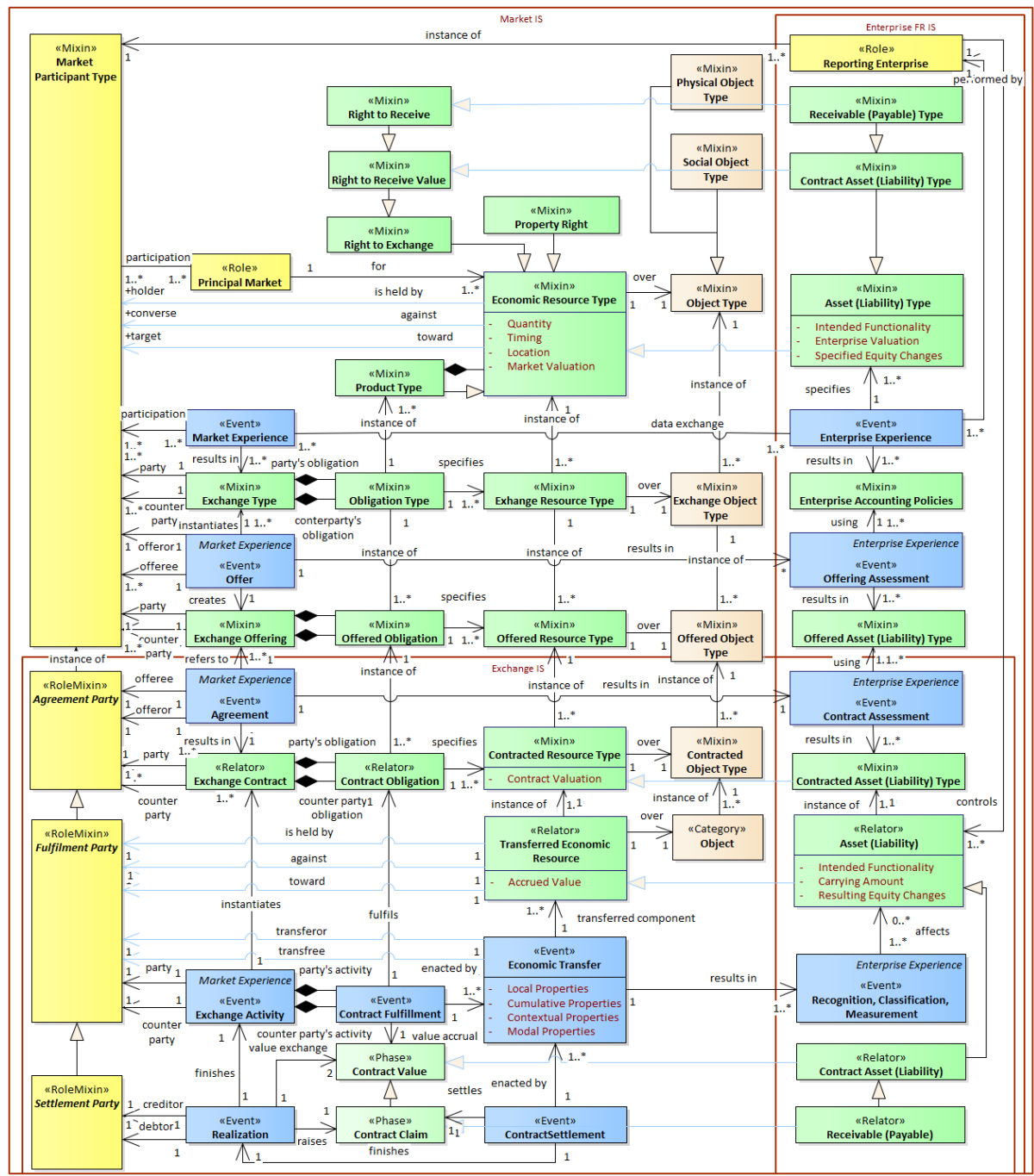

Fig. 4. COFRIS. OntoUML diagram of Market, Exchange, and Enterprise FR IS fragment.

Individual Market Participants - OFFERORs specialize/instantiate Exchange Types and offer ECONOMIC RESOURCE TYPEs for exchange in the Market to the OFFEREEs via EXCHANGE OFFERINGs. Exchange Offerings form a part of Market Experience and in FR can be regarded as a source of Market based Valuation.

The PARTIES of an EXCHANGE TYPE can be non-related, related, or represent different roles of the same MARKET PARTICIPANT. 


\subsection{Exchange Information System}

ECONOMIC EXCHANGE is conceived as a competitive OFFERING of EXCHANGE TYPE made by an OFFER of a PARTY to other PARTIES, possibly followed by AGREEMENT with the COUNTERPARTY resulting in a consensual EXCHANGE CONTRACT of mutually beneficial and correlative EXCHANGE OBLIGATIONs to TRANSFER ECONOMIC PRODUCT (OBLIGATIONS) of a SPECIFIED TYPE in exchange for agreed VALUATION.

EXCHANGE CONTRACT integrates PARTY's and COUNTERPARTY's EXCHANGE OBLIGATIONs and is instantiated by EXCHANGE ACTIVITY that consists of:

- FULFILLMENT of both Parties' Obligations by Transfer of Economic Resources (Obligations), that are instances of specified Resource (Obligation) Types, in exchange for an agreed Value Accrual for the Transfer;

- Realization - Contract Value AcCrual exchange among Parties, caused by complete Fulfillment of Contract Obligations by first Party who becomes CREDITOR, and resulting in raising ECONOMIC ClAIMs against the Other Party who becomes DEBTOR for its unfulfilled Obligations,

- SetTlement - enforceable fulfillment of these Claims by Transfers by Debtor.

- or BREACH or SUSPENSION of the Contract by one of the Parties during Fulfillment or Settlement.

Economic TRANSFER event either conveys the Rights (Obligations) over an Object or the usage (service) of such Rights from the TRANSFEROR to the TRANSFEREE.

A TRANSFEROR under certain conditions can transfer not only its Resources, but also its Obligations - the Resources held AGAINST TRANSFEROR. For example, an Enterprise can settle income tax obligations of an Employee in exchange for the settlement of Employee's payroll claims against the Enterprise.

CONTRACT VALUATION is the agreed Transaction Price that is accrued for the Transfer, it could be (1) Fixed; (2) based on the Market Price that is the Market Valuation that could be received (paid) in the Market for similar (offered) or specific Transfer; or (3) based on disclosed Historical Cost of the Transferred Resources (Obligations).

See [7] for the specific Economic Exchange examples in COFRIS.

\subsection{Enterprise Information System and Enterprise-Specific Accounts}

An ENTERPRISE-SPECIFIC Exchange effects situation is depicted on the right side of Fig. 4. Market exchange events together with market other events or conditions (such as regulation, market participant, market resource and price changes), and enterprise-specific and underlying object changes, affect ENTERPRISE-SPECIFIC ECONOMIC RELATORs.

UNITS OF ACCOUNT - ASSETs (LIABILITIES) are present RIGHTs (OBLIGATIONs) for RESOURCEs controlled (OBLIGATIONs indebted and unavoidable) by the ENTERPRISE, as a result of past activities which form their HISTORICAL COST [2] and ENTERPRISE EXPERIENCE. CARRYING AMOUNT represents the present VALUATION that is measured based on the MARKET and ENTERPRISE EXPERIENCE.

Changes of ASSETs (LIABILITIEs) are specializations of Transfers of Resources (Obligations), extended by CONTROLLED and INTENDED FUNCTIONALITY, such as usage of the assets for enterprise activities of administration, sales of goods and rendering services and production, in specified roles, such as of raw materials, equipment and labor. 
EQUITY CHANGES, including INCOME and EXPENSEs, characterize performance aspects of Asset (Liability) changes and the Role performed - Nature in a Performed activity - Function.

CONTROL is a valuable capability of the ENTERPRISE "to direct the use of the Economic Resource and obtain the Economic benefits that may flow from it" [2]. Thus, Assets inhere in the ENTERPRISE. Asset's disposition, enough (assez) to play a role in controlling Enterprise's activities:

- is constrained by the rights, abilities, regulations, intentions of the Enterprise;

- is increased by the Enterprise's synergies in combination with other, possibly unrecognized, assets or legal rights and tax benefits;

- accumulates Enterprise's economic experience of the Asset Type or an item;

- is protected from unauthorized use or transfer by other Market Participants.

While all exchanged Resources are Enterprise Asset (Liability) changes in Financial Reporting, some are regarded as MOMENTARILY [2,3], i.e., are transferred or consumed as received. MOMENTARILY ASSETS, such as services, increase the Carrying Amount of the affected Assets. Other Asset (Liability) changes are recognized for future recovery (Transfer) or derecognized.

Classification, VAluation, and UnCERTAinty of ASSETs (LIABILITIEs) depend on the enterprise intended activities and roles, the MARKET and ENTERPRISE EXPERIENCE, and can change as a result of ASSET (LIABILITY) enhancement/impairment and MARKET and own prices and risks. The MARKET VALUATION input is either probability weighted and/or discounted at a rate that reflects risk and UNCERTAINTY for ENTERPRISE VALUATION but is not purported to be a prediction.

\section{$4 \quad$ Analysis and Suggestions for a Shared Perspective in FR Conceptual Framework and Standards}

In March 2018 International Accounting Standards Board (IASB) released the revised version of the Conceptual Framework (CF) for Financial Reporting. It describes the objective of, and the concepts for, general purpose financial reporting. The purpose of the $\mathrm{CF}$ is to [2]:

- assist the IASB to develop IFRS Standards that are based on consistent concepts;

- assist preparers to develop consistent accounting policies when no Standard applies to a particular transaction or other event, or when a Standard allows a choice of accounting policy; and

- assist all parties to understand and interpret the Standards.

Our goal is to be reasonably compliant with the framework in engineering COFRIS. Another goal is to see where the CF could benefit from our ontological analysis. Here are some preliminary suggestions for a framework in a shared environment.

1. Types of Economic Phenomena. We argue that a FR system should base on a shared Market, Exchange, and Enterprise Information System that captures interrelated Economic phenomena relevant for FR. The automatically provided Market IS and Exchange 
IS information is preferred because access to the history of market transactions, participants and objects, that allows for objective and symmetrical typification and valuation. This doesn't exclude the Enterprise from augmenting the Market and Exchange IS information. The Standards should determine which kinds of Market IS Sources, Exchange Types and Provenance Registers can be used for specialization/instantiation, recognition, classification and valuation.

2. Lifecycles of Economic Phenomena. The Information System should cover full Exchange lifecycles and Object provenance histories. The Enterprise FR IS should capture Offering, Contract and Exchange Activity information in related and systematic way, including types and phases of OFFERED, LAPSED, CONTRACTED, BREACHED and SUSPENDED in addition to RECOGNIZED Units of Account.

3. Capturing Economic Event Qualities. Financial Reporting can aggregate transaction-centric plus Enterprise-Specific, instead of exclusively Enterprise effect-centric information. Aggregation of consensual transactions for Financial Reporting, instead of accounts, provides additional opportunities for creating Exchange Types and Provenance Registers, comparability among market participant and among different period processes, possibilities of application of process mining methods, disclosure of eventspecific information [18] and insights into the processes of value co-creation.

Object and Economic Resource QUANTITY is a fundamental feature of Economic Events [4]. However, it is not defined in CF for Assets, Liabilities and Equity Changes.

The event information makes the MOMENTARILY ASSETs concept redundant.

4. Correlative and Consensual standards and information. Consensuality - meaning that among parties there is an agreed shared ledger of Contracts and their Fulfillment, including Resources (Obligations) and required Asset (Liability) information - can be a quality aspect, even within the old context of audit reconciliations. Consensuality can be added to comparability, verifiability, timeliness, and understandability as a qualitative characteristic that enhances the usefulness of information that both is relevant and provides a faithful representation of what it purports to represent and reduces reporting uncertainty. When correlativeness and consensus are not regarded as a standard-setting principle, deficiencies emerge in standards already discussed by us elsewhere, such as those concerning Leases, Contract Assets and Revenue [7].

The consensual information about related Market Participants, the information of whether one Enterprise is a subsidiary of another, or one Enterprise's CEO is a board member of another company, must be deducible from the Market IS or declared and agreed by the involved parties.

5. Avoidance of enterprise-sensitive information disclosure. Providing information to Market IS or Exchange IS may disclose sensitive information (i.e. information whose disclosure could result in commercial loss to an enterprise). A similar problem exists now within FR. The IASB does not currently have a general approach to information sensitivity. Widening the amount of disclosed information requires a specialization of FR ontology for sensitive information. The immediate conclusions from our ontology is that in Exchange IS, a disclosure of one party's information leads to automatic disclosure of the counterparty's information. The disclosure in one phase of economic exchange leads to possible disclosures in other phases, and the disclosure in one provenance event leads to possible disclosures in other events. The Market experience should be based rather on type than instance information, which lowers the sensitiveness of information. 6. Increase of the FR user scope. Regarding the Objective of the FR (Section 1), we argue that the users of the FR are not only "the existing and potential investors or creditors" but any Market Participant who wants to make Offerings, conclude and execute Contracts with the Enterprise. Moreover, in a Market IS all participants that want to use 
Exchange Type and Provenance Register information are users of FR. In addition, the focus of the FR moves from Shareholders to Stakeholders.

7. Transfer of Economic Resources. The CF defines Liability and other obligations as "a duty and responsibility to transfer Economic Resources", while TYPES of Economic Resources are implied.

8. "Transfer" of Assets and Liabilities. Assets and Liabilities cannot be transferred as metaphorically stated in some Standards [1], because they inhere in the Enterprise, but the rights that an Enterprise is capable to transfer or to use are the Resources of the Asset. 9. Exchange and Transfer of Obligations. Per CF [2], "An executory contract establishes a combined right and obligation to exchange economic resources [of the reporting entity and the other party]. The right and obligation are interdependent and cannot be separated". We argue that a contract can establish an exchange of economic resources and/or economic obligations of an enterprise.

10. Different Rights to Receive: Contracts, Products, Resources. Further, regarding Contracts, CF States that "If the reporting entity performs first under the contract, that performance is the event that changes the reporting entity's right and obligation to exchange economic resources into a right to receive, an economic resource. That right is an asset. If the other party performs first, that performance is the event that changes the reporting entity's right and obligation to exchange economic resources into an obligation to transfer an economic resource. That obligation is a liability".

We argue that different classes of rights to receive and obligations to transfer exist and are common to all contracts and thus standards, and are first-class candidates for becoming concepts in CF. Primarily, a transfer of an Economic Resource (or Obligation) leads to a Right to receive Value for the transferred Resource, that Right is a Contract Asset. Secondarily, it can be a Right to receive Revenue, if a Product is transferred, so it can be different - a Contract Performance Asset. And thirdly, it is an Unconditional Right for Consideration, if the Contract is fulfilled, that Right is a Receivable Asset. These concepts are missing in CF, the Contract Asset and Receivable are present in other IFRS Standards, but they do not differentiate among Contract and Performance Assets.

\section{Conclusions}

The specific contribution of this paper is the introduction of the concept of Market IS, in addition to the Exchange IS (shared ledger) and the Enterprise-Specific IS, and a corresponding partitioning of the accounting ontology. We expect Market IS and shared ledger IS to become more and more important, but if these are being built as ad-hoc extensions of Enterprise-Specific IS, or just stand-alone applications, a sound ontological basis is missing. This would hinder future integration and interoperability.

With regards to our research questions, we have argued that the shared information system is more objective (neutral), doesn't need audit (or much less), accumulates experience, context and history from events, participants, resources and objects, and so increases the quality of the information system. The UFO-compliant ontology is worked out in Section 3. In Section 2, we have given an overview of available ontologies and frameworks from which we have made use. In Section 4, we have indicated some deficiencies in the current FR framework on the basis of our ontology.

Within the limits of this article, we have not been able to work out an extensive example to see concretely how the different IS parts materialize and where they connect. This is a topic for future research. Apart from an example, there is also a need to work out a 
system architecture to integrate the different IS. Standard bodies may have a role in implementing system architecture requirements.

\section{References}

1. IASB homepage, http://www.ifrs.org/issued-standards/list-of-standards, IASB, 2019

2. IASB Conceptual Framework for Financial Reporting, IASB, 2018.

3. FASB Conceptual Framework for Financial Reporting, FASB, 2016.

4. Ijiri, Y., Theory of Accounting Measurement. American Accounting Association, 1975.

5. Blums, I., H. Weigand: Towards a Reference Ontology of Complex Economic Exchanges for Accounting Information Systems. EDOC 2016: 119-128.

6. Blums, I., Weigand, H.: Towards a core ontology for Financial Reporting information systems (COFRIS). OTM 2017 Workshops, LNCS 10697: 302-306, 2018.

7. Weigand, H., I. Blums, J. de Kruijff: Shared Ledger Accounting - Implementing the Economic Exchange Pattern in DL Technology. CAiSE 2018: 342-356.

8. The PROV Ontology. W3C Recommendation. https://www.w3.org/TR/prov-o/.

9. Weigand, H., Elsas Ph.: Auditability as a Design Problem. IEEE CBI 2019:11-20.

10. Weigand, H., The e3value Ontology for Value Networks: Current State and Future Directions. AIS Journal of Information Systems. 30, 113-133 (2016).

11. Wieringa, R.J., W. Engelsman, J. Gordijn, D. Ionita, A Business Ecosystem Architecture Modeling Framework. CBI 2019:1-10.

12. Guizzardi, G.: Ontological foundations for structural Conceptual Models. Ph.D. thesis, CTIT, Centre for Telematics and Information Technology, Enschede (2005).

13. Guizzardi, G., et al, Endurant Types in Ontology-Driven Conceptual Modeling: Towards OntoUML 2.0, ER 2018, Xi'an, China.

14. Nardi, J.C., et al., A commitment-based reference Ontology for services. Inf. Syst. 54, $263-$ 288 (2015).

15. Sales, T., et al., Towards and Ontology of Competition, VMBO 2018, Amsterdam, 2018.

16. Criffo, C., Almeida, J.P.A., Guizzardi, G., From an Ontology of Service Contracts to Contract Modeling in Enterprise Architecture, EDOC 2017.

17. Almeida, J.P.A., R. A. Falbo, G. Guizzardi, Events as Entities in Ontology-Driven Conceptual Modeling. ER 2019: 1-14.

18. Guarino, N., On the Semantics of Ongoing and Future Occurrence Identifiers. ER 2017: 477-490.

19. Guarino, N., Guizzardi G. (2016) Relationships and Events: Towards a General Theory of Reification and Truthmaking. AI*IA 2016. LNCS, vol 10037. Springer, Cham.

20. Azevedo, C.L.B. et al: Modeling resources and capabilities in Enterprise architecture: A well-founded ontology-based proposal for ArchiMate. Inf. Syst. 54: 235-262 (2015).

21. Almeida, J.P.A., et al., Multi-Level Conceptual Modeling. ONTOBRAS 2018: 26-41.

22. Melse, E., The Financial Accounting Model from a System Dynamics' Perspective, mpra.ub.uni-muenchen.de, 2006.

23. Appelbaum, D, Nehmer, R.: Designing and Auditing Accounting Systems Based on Blockchain and Distributed Ledger Principles. Feliciano School of Business (2017).

24. Dai, J., Vasarhelyi, M.: Toward Blockchain-Based Accounting and Assurance. Journal of Information Systems, 31(3), 5-21 (2017).

25. The Open Group, “Archimate 3.0 specification,” Standard, 2016.

26. ISO/IEC FDIS 15944-4: 2015. Information Technology - Business Operational View Part 4: Business Transactions Scenarios - Accounting and Economic Ontology. ISO 2015.

27. Financial Industry Business Ontology: Foundations Version 1.2, OMG 2017.

28. Fischer-Pauzenberger, C., W.S. A. Schwaiger, The OntoREA Accounting Model: Ontologybased Modeling of the Accounting Domain. CSIMQ 11: 20-37 (2017). 